\title{
O CURRÍCULO ACADÊMICO
}

Zélia Milléo Pavão*

Um dos grandes filósofos contemporâneos, Herbert Marcuse escreveu um livro cujo título - O HOMEM DE UMA SÓ DIMENSÃO, levou filósofos e sociólogos a retomarem a discussão sobre a inserção do fenômeno sociológico numa reflexão filosófica, a partir da idéia central de que o homem não é simplesmente um ser que cria mecanicamente os fatos sociais, mas é um ser relativamente livre, que faz história, tende a realizar seus projetos e se empenha no possível. Desse modo, pode-se inferir que, na história e até hoje, o homem se define por suas dimensões: a do real e a do possível.

Que se esteja ou não de acordo com as análises contidas na obra de Marcuse, a tese tem o grande mérito de alertar para o perigo de uma redução quase total da dimensão humana do possível à dimensão do real: os homens acabariam, então, por estarem de tal modo adaptadas a realidade que só existiria uma dimensão, a da submissão à ordem existente. ( Goldmann, 1984).

Esta reflexão inspirada na obra de Lucien Goldmann EPISTEMOLOGIA E FILOSOFIA POLÍTICA - não deve ser apenas do domínio da Filosofia e da Sociologia, mas também, da Ciência da Educação.

A teoria do currículo é o fórum da educação para discussão das dimensões a que o homem deve ser elevado para começar o próximo século com a dignidade que lhe é inerente.

A concepção de currículo evoluiu acompanhando o desenvolvimento das ciências da educação aplicadas a diferentes áreas do conhecimento.

A questão fundamental no âmbito dos estudos sobre currículo resume-se na explicação do que deve ser aprendido (conteúdo) e do como deve ser aprendido (ação).

Segundo HILDA TABA (1974), a elaboração de um currículo não é

* Professora Doutora do Mestrado em Educação da Pontifícia Universidade Católica do Paraná 
um procedimento arbitrário pois as decisões tomadas no seu planejamento deverão ter por base critérios provenientes de distintas fontes: a tradição, as pressões sociais e os hábitos estabelecidos.

A observação de que há semelhanças visíveis entre as novas idéias de educação, currículo e aprendizagem da atualidade com as da década de 30, levou TABA (1974) a organizar seu trabalho de pesquisa com objetivo de examinar a teoria da evolução do currículo, e a interface com as outras áreas do conhecimento. Embora considere que grande parte das decisões sobre as transformações na organização do currículo são aceitas por pressões , opiniões, convivências e não se fundamentam em concepções teóricas definidas ou conhecimentos comprovados.

Devido à esterilidade e a inflexibilidade que geralmente se associam à elaboração do currículo por matéria, tem-se dado pouca atenção às maneiras possíveis de interface da organização lógica do conteúdo com a configuração psicológica da aprendizagem ou os critérios lógicos do conhecimento.

As conseqüências tanto da inflexibilidade como da fragmentação resultante da atomização do conhecimento na organização do currículo por matéria, começam a ser seriamente criticadas, principalmente no aspecto que se refere à natureza do conteúdo; na sua orientação acadêmica; na sua persistência na exposição; nos fatos e na concepção limitada da natureza da aprendizagem.

Outro aspecto importante na teoria da elaboração do currículo é a metodologia do processo. As metodologias propostas têm recebido críticas em diferentes aspectos. Ora critica-se a falta de seqüência racional na abordagem da variedade de tarefas que compreende a elaboração do currículo; ora a crítica é dirigida à seqüência de se começar pela formulação do projeto e de uma estrutura para em seguida desenvolver as unidades de aprendizagem. Alega-se que, desse modo, reduzem-se as possibilidades da inovação criativa da qual podem surgir novas idéias e novos conceitos sobre currículo.

As inovações criativas podem não ocorrer quando se tomam decisões sobre "como estabelecer coerência entre os objetivos e o que se ensina, ou se traduzem as idéias de aprendizagem em seqüências, após se ter definido a estrutura curricular, principalmente se tais decisões são tomadas por educadores sob condições que não estimulam o pensamento teórico.

Uma seqüência metodológica não apropriada e as decisões dicotomizadas sobre os conteúdos e os métodos são fatores responsáveis pela limitação da aplicação de critérios preliminarmente aceitos. Esta limitação ocorre, por exemplo, com o conceito de desenvolvimento: enquanto o critério de uma seqüência é aperfeiçoado nas grades curriculares mais atualizadas, sua aplicação pode ser limitada pelo conceito de disposição e pelo ensino de algumas matérias; ou a seqüência evolutiva na aprendizagem apenas foi analisada. 
Pode ainda, ocorrer que o conceito das diferenças no desenvolvimento mental pode ser aplicado somente na modificação do ritmo e na quantidade da aprendizagem, enquanto que não se modificam a qualidade da compreensão nem a profundidade da percepção. Desse modo, a distância entre a teoria e a prática pode existir em ambos extremos da elaboração do currículo: isto é, o planejamento teórico do currículo é formulado sem base em pesquisa que sistematize e de condições de análise profunda da realidade sobre a qual a observação assistemática não é suficiente, conduzindo a erro de aplicação inadequada da teoria. Em outras palavras, a falta de uma teoria condizente com a realidade conduz a prática de ser considerada somente a forma e não a substância, subvertendo-se a essência da idéia.

Basicamente o problema principal no planejamento do currículo não deve consistir no planejamento em si, mas na maneira inteligente e científico de se trabalhar sobre a base de fatos e critérios racionalmente reconhecidos em lugar de se deixar guiar por outra mescla de suposições, crenças e preferências pessoais.

Autores contemporâneos, como Michael Apple e Henry Giroux (in Moreira e Silva, 1995), introduzidos recentemente na bibliografia brasileira sobre currículo, têm preocupação de natureza sociológica e ideológica e representam, em diferentes graus, tendências oposicionais que correspondem a rupturas na dominação hegemônica.

Embora tenha havido importantes modificações nas formas de conceber o conhecimento e a linguagem, com profundas implicações para a teorização do currículo, na visão que está ligada às suas concepções convencionais, o conhecimento e a linguagem são vistos como representação e reflexo da realidade e se fundamentam em modelo racionalista do sujeito e da consciência.

O movimento pós-modernista, denominado "virada lingüística", vem colocar em xeque as concepções que constituem o núcleo do que deve ser a noção de educar, e de currículo.

A contestação pós-moderna coloca em evidencia o papel das "grandes narrativas" e da noção de razão e de racionalidade que têm sido centrais ao projeto cognitivo moderno e ao conhecimento educacional (currículo). Nesta visão é a linguagem, o discurso e o texto que ganham importância central, cujas conseqüências, tanto na forma de analisar o currículo como também na de organizá-lo, não têm sido suficientemente exploradas (APPLE e GIROUX, IN Moreira e Silva, 1995).

O currículo dos "grandes temas gerais" constitui essencialmente, um esforço para superar a compartimentação e a atomização do currículo, mediante a combinação de alguns campos específicos no interior de áreas mais amplas.

A integração do conhecimento é importante, tanto do ponto de vista 
da explosão e da especialização do conhecimento, como da repercussão social da explosão tecnológica. Portanto é indispensável que o currículo possibilite o desenvolvimento de "hábitos mentais" que permitam que, dos princípios válidos para uma área, deduzam-se fatos, em outra, mas, para que isso ocorra, será necessário a presença de um fator comum para a comunicação entre pessoas comprometidas com diferentes aspectos especializados do esforço humano.

Conclui-se da postura de ambos cientistas que a teorização crítica sobre currículo, da qual a sociologia é um importante elemento, é um processo contínuo de análise e reformulação ressaltando ainda a fragilidade de qualquer proposição curricular que queira abarcar o aqui, o agora e o sempre.

Para desenvolver uma teoria sobre a elaboração do currículo e um método de concebê-lo é indispensável investigar quais são as demandas e os requisitos da cultura e da sociedade, tanto para o presente como para o futuro. O currículo deve ser visto como uma maneira de preparar a juventude para participar ativamente de sua cultura. Nem todas as culturas se nutrem das mesmas classes de conhecimentos, nem uma mesma cultura necessita dos mesmos tipos de capacidades e habilidades intelectuais em todas as épocas. Assim, uma análise da cultura e da sociedade é um dos critérios que fundamentam a proposta de currículo.

Outro critério é a informação sobre o processo de aprendizagem e a natureza do sujeito aprendiz.

A terceira fonte de critérios para a adoção de decisão sobre o currículo é a natureza do conhecimento.

Em termos práticos, pode-se propor três dimensões para a elaboração de um currículo de curso superior;

- a formação geral;

- a formação específica;

- a formação continuada.

Um curso superior deve pretender que o futuro profissional receba uma sólida formação teórica-prática que lhe permita atuar com competência técnica e compromisso profissional e político na atual realidade brasileira. Para tanto, será necessário que o futuro profissional tenha acesso a uma formação básica e profissional que lhe prepare para o exercício da cidadania.

A formação geral estará dirigida para o processo de construção e apropriação de conteúdos e de conceitos relativos ao contexto histórico, social, político, cultural, econômico e educacional.

A formação específica centrada em conteúdos próprios da área de conhecimento.

A formação continuada envolverá o seu papel de agente transformador da história e um pesquisador de sua própria prática.

Enfim, tal profissional necessita possuir características tais como: 
- adquirir cultura geral e específica;

- ser coerente crítico e agente transformador;

- ser equilibrado emocionalmente;

- ser um pesquisador;

- participar de aperfeiçoamento constante.

\section{Referências Bibliográficas}

GOLDMANN, Lucien. Epistemologia e filosofia política. Porto Editorial Presença, 1984.

APPLE, Michael \& GIROUX, Henry. In: MOREIRA e SILVA (Org.). Currículo, cultura e sociedade. 2 ed. São Paulo: Cortez, 1995.

TABA, Hilda. Elaboración del currículo. Teoria y prática. Ediciones Troquel S.A., Buenos Aires, 1974. 